\title{
Modified Instantaneous Power Theory and Fuzzy Logic Based Controller for Grid-connected Hybrid Renewable Energy System with Shunt Active Power Filter Functionality
}

\author{
Jayasankar $\mathrm{V} \mathrm{N}^{1}$ and Vinatha $\mathrm{U}^{2}$ \\ ${ }^{1}$ Department of Electrical \& Electronics Engineering, \\ The National Institute of Engineering Mysuru , India - 570008 \\ ${ }^{2}$ Department of Electrical \& Electronics Engineering \\ National Institute of Technology Karnataka Surathkal, India - 575025
}

\begin{abstract}
This study suggests a controller for grid connected hybrid renewable system with shunt active filter functionality. The controller consists of a modified pq theory based inner loop and an adaptive fuzzy logic based outer loop. Positive sequence sinusoidal signal regulator and self tuning filter are employed for making the controller work satisfactorily under unbalanced and distorted grid voltage conditions. In order to verify the effectiveness of controller under different system conditions, numerical simulations are carried out for different cases. A laboratory prototype is developed and tested under steady state condition, and the results are found to be satisfactory.
\end{abstract}

Keywords: Renewable energy system, Shunt active filter, Adaptive fuzzy control, Instantaneous power theory, Self tuning filter, Positive sequence sinusoidal signal regulator

\section{Introduction}

Exhausting fossil fuels and increasing energy demand made the researchers and energy engineers think about alternative renewable energy sources. Most commonly used renewable sources are wind and solar. The hybrid combination of wind and solar is preferred as wind and solar generations are complementary to each other. Instead of using individual inverters for the grid integration of wind and solar systems, dc shunted single inverter scheme can be used, to reduce the overall cost [1]. Use of non-linear loads at load centers adversely affects the power quality in distribution systems. Shunt active filters at the point of common coupling (PCC) compensates the harmonic currents, and makes the grid current sinusoidal. If the grid interfacing inverters of renewable systems at the distribution level can be used as shunt active filters, the power quality problems can be resolved with no additional investment for shunt active filters. Grid interfacing inverter with shunt active filter functionality consists of a multi-loop control system; the faster inner current control loop for active filtering and a slower outer dc-link voltage control loop for power flow control from renewable system to grid.

Instantaneous power theory was proposed by H. Akagi et al. in 1984, for inner loop control in shunt active filters [2]. The main drawback of this theory is, the performance of the controller is unsatisfactory under unbalanced and distorted grid voltage conditions. Synchronous reference frame method is an alternative method for inner loop control, but it requires an additional phaselocked loop system, a dq transformation and inverse dq transformation calculations [3]. A modified pq theory-based inner loop control with positive sequence sinusoidal signal regulator (PSSR) makes the controller work satisfactorily under unbalanced and distorted grid conditions [4]. DC link voltage control can be done using PI controller for power flow control and power balancing in a shunt active filter [5]. The adaptive fuzzy logic controller is an alternative method for the outer loop control of shunt active filters, for better dynamic performance and adaptability to system parameter changes [6].

In this study, the shunt active filter control techniques are modified and applied for the gridconnected renewable systems at the distribution level. The inner loop consists of instantaneous power theory based controller with PSSR and self-tuning filter. PSSR is employed to make the system work satisfactorily under unbalanced and distorted grid voltage conditions, and self-

Received: June $1^{\text {st }}, 2018$. Accepted: June $15^{\text {th }}, 2019$

DOI: 10.15676/ijeei.2019.11.2.10 
tuning filter is employed for improving the fundamental current calculation, as it introduces no phase delays like low pass filters. The adaptive fuzzy controller is used in the outer loop, for dclink voltage control. The fuzzy controller is designed to offer better dynamic performance when a generation or load changes happen. Hysteresis controller is used for generating pulses of the inverter.

\section{System Descriptions}

The system under study consists of a wind farm, a solar PV array, dc-dc converters, uncontrolled rectifier, dc-link capacitor, a three-phase four-leg inverter, ac filter, non-linear loads and distribution level power grid. Figure 1 shows the schematic diagram of the overall system.

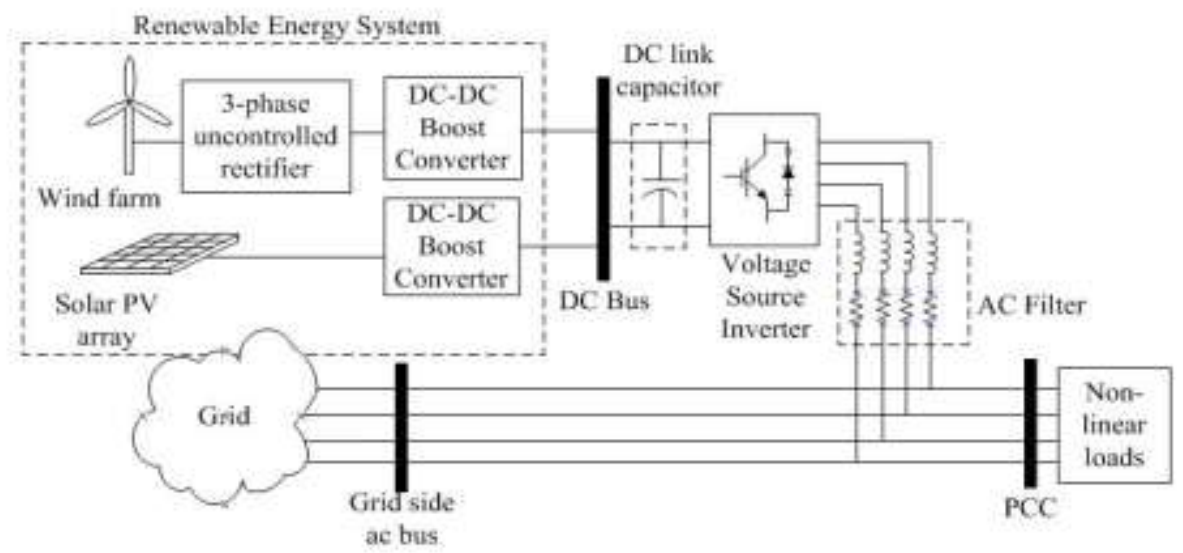

Figure 1. Schematic diagram of the overall system under study

\section{A. Wind farm}

The wind farm consists of wind turbines coupled with generators. Permanent magnet synchronous generators (PMSG) are widely used in wind farms because they have high efficiency and low weight. The generator output is converted to dc using a three-phase uncontrolled rectifier and using dc-dc boost converters, a constant dc voltage is maintained. The boost converter output is connected to a common dc bus [7], [8], [9], [10].

\section{B. Solar farm}

Series and parallel solar PV cell arrays are present in solar farms. The energy generation directly depends on the solar irradiation. DC-DC boost converters are used for maintaining a constant dc voltage, and the output is connected to a common dc bus [11], [12], [13].

\section{DC link capacitor and ac filter}

DC link capacitors are employed to reduce the dc voltage ripples. It also works as an energy storage element in transient time. DC ripples reduce as capacitor size increases, but the dynamic performance of the system gets adversely affected by an increase in capacitor size. The capacitor value can be optimally designed using (1), where " $\mathrm{E}_{\max }$ is the maximum energy that the capacitor has to supply during transient condition".

$$
C_{d c} \geq \frac{2 E_{\max }}{u_{d c}^{2}-u_{d c \min }^{2}}
$$


AC filter suppresses the switching harmonics and high-frequency signals present in the inverter output. The ac inductor filter can be designed using (2).

$$
L_{c}=\frac{u_{d c}}{6 f_{c} \Delta I_{p p \max }}
$$

Where, " $\Delta \mathrm{I}_{\mathrm{ppmax}}$ is the maximum ripple current, $\mathrm{f}_{\mathrm{c}}$ the switching frequency, and $\mathrm{U}_{\mathrm{dc}}$ is the $\mathrm{dc}$ link voltage".

\section{Voltage source inverter}

Three-phase, four-leg IGBT inverter is used as grid interfacing inverter. The fourth leg is for neutral current compensation, which helps in load balancing. Next section discusses the control system used for switching control of inverter.

\section{Design of control system}

The control system consists of mainly two loops, an outer voltage control loop and an inner current control loop. Figure 2 shows the overall schematic diagram of the control system. The main objectives of the control system are (i) to maintain the dc-link voltage and balance the power flow, (ii) to compensate the harmonic components of load current at PCC.

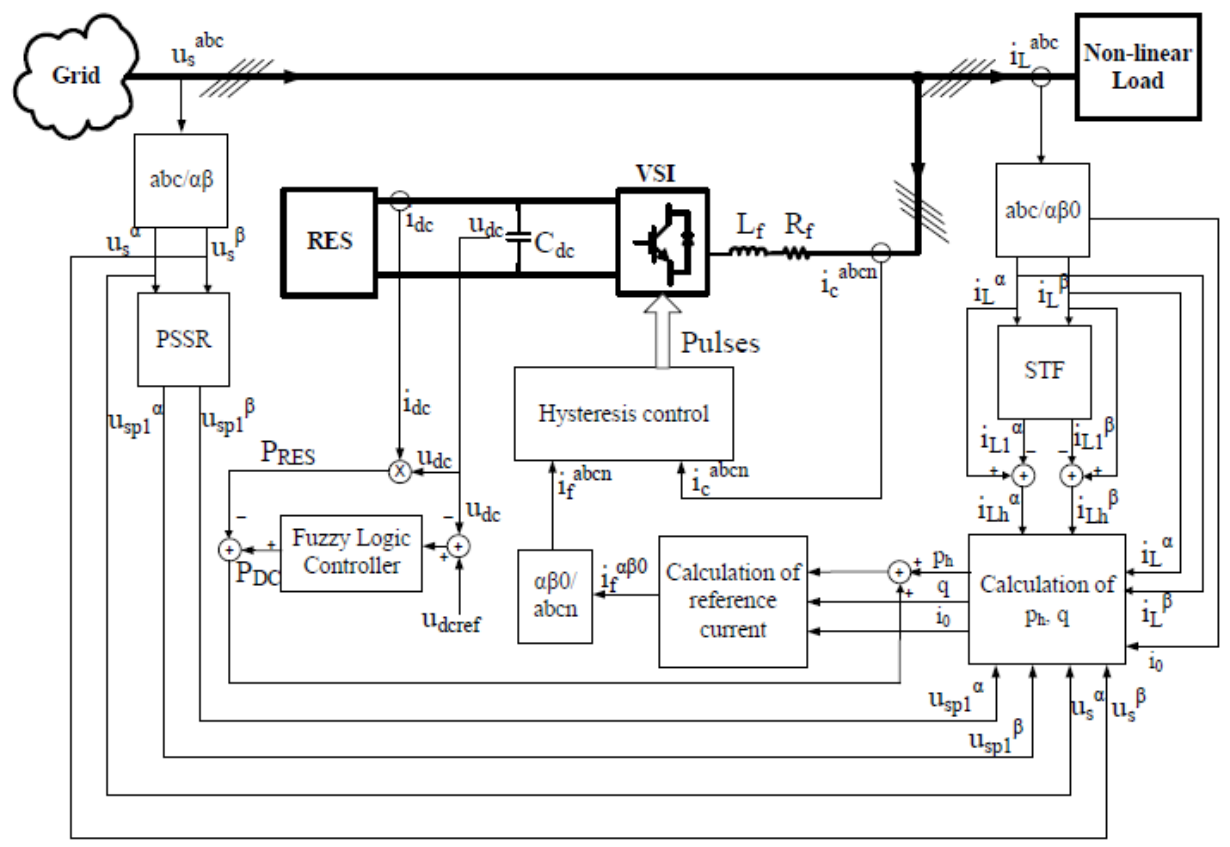

Figure 2. Schematic representation of control system

\section{A. Outer control loop design}

The objective of outer loop control is maintaining the dc-link voltage constant, and power flow balance in the system. DC link voltage and the reference voltage values are compared and the error signal is processed using a non-linear adaptive fuzzy controller. For each input and output variables; -ve big (NB), -ve medium (NM), -ve small (NS), zero error (ZE), +ve small (PS), +ve medium (PM) and +ve big (PB) fuzzy levels are chosen. Membership functions are normalized by multiplying with control gains. Normalized input and output membership functions are shown in Figure 3. 

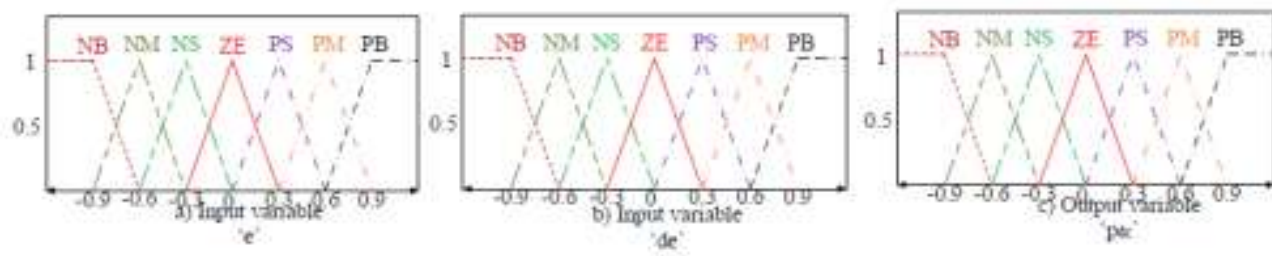

Figure 3. Normalized membership functions of a) Input variable 'e',

b) input variable 'de' and c) Output variable ' $\mathrm{p}_{\mathrm{dc}}$ '

Fuzzy rule table is formed as shown in Table 1 based on the fact that control output should be large if the error is large, and fine control when the error is small [6]. Fuzzy rules are formed according to the rule table.

Table 1. Fuzzy Rule Table

\begin{tabular}{|l|l|l|l|l|l|l|l|}
\hline $\begin{array}{l}\text { de } \\
\text { de }\end{array}$ & NB & NM & NS & ZE & PS & PM & PB \\
\hline NB & NB & NB & NB & NB & NM & NS & ZE \\
\hline NM & NB & NB & NB & NM & NS & ZE & PS \\
\hline NS & NB & NB & NM & NS & ZE & PS & PM \\
\hline ZE & NB & NM & NS & ZE & PS & PM & PB \\
\hline PS & NM & NS & ZE & PS & PM & PB & PB \\
\hline PM & NS & ZE & PS & PM & PB & PB & PB \\
\hline PB & ZE & PS & PM & PB & PB & PB & PB \\
\hline
\end{tabular}

Centroid method is used for defuzzification. Output control gain is adjusted to get the output $\mathrm{P}_{\mathrm{DC}}$, which represents the power flow to the capacitor for keeping dc-link voltage constant. The power from renewable sources $\mathrm{P}_{\mathrm{RES}}$ flows towards the dc-link capacitor. So the total power flown from inverter to dc capacitor is $\mathrm{P}_{\mathrm{DC}}-\mathrm{P}_{\mathrm{RES}}$.

\section{B. Inner control loop design}

The load currents and grid voltages are sensed and transformed into $\alpha \beta$ frame using (3) and (4). Where $i_{L}{ }^{a}, i_{L}{ }^{b}, i_{L}{ }^{c}$ and Where $u_{s}{ }^{a}, u_{s}{ }^{b}, u_{s}^{c}$ are load currents and grid voltages respectively. $i_{L}{ }^{\alpha}$, $i_{L}{ }^{\beta}, i_{L}{ }^{0}$ and $u_{s}^{\alpha}, u_{s}^{\beta}$ are the load currents and grid voltages in $\alpha \beta$ frame.

$$
\begin{aligned}
& {\left[\begin{array}{c}
i_{L}^{\alpha} \\
i_{L}^{\beta} \\
i_{L}^{0}
\end{array}\right]=\sqrt{\frac{2}{3}}\left[\begin{array}{ccc}
1 & -1 / 2 & 1 / 2 \\
0 & \sqrt{3} / 2 & -\sqrt{3} / 2 \\
1 / \sqrt{2} & 1 / \sqrt{2} & 1 / \sqrt{2}
\end{array}\right]\left[\begin{array}{c}
i_{L}^{a} \\
i_{L}^{b} \\
i_{L}^{c}
\end{array}\right]} \\
& {\left[\begin{array}{c}
u_{S}^{\alpha} \\
u_{S}^{\beta} \\
u_{S}^{0}
\end{array}\right]=\sqrt{\frac{2}{3}}\left[\begin{array}{ccc}
1 & -1 / 2 & 1 / 2 \\
0 & \sqrt{3} / 2 & -\sqrt{3} / 2 \\
1 / \sqrt{2} & 1 / \sqrt{2} & 1 / \sqrt{2}
\end{array}\right]\left[\begin{array}{c}
u_{s}^{a} \\
u_{S}^{b} \\
u_{S}^{c}
\end{array}\right]}
\end{aligned}
$$

The unbalance or distortions in grid voltages affect the performance of control system. PSSR is employed to address this problem. PSSR is a sinusoidal signal integrator (SSR) with negative loop feedback as shown in Figure 4 [4], [14]. If the resonance frequency $\omega$ of SSR matches with the input signal frequency, it integrates the signal; else the integration output is zero. The negative feedback is provided to give regulator functionality and thus identifies the positive sequence fundamental component of the signal. $\mathrm{u}_{\mathrm{sp} 1}{ }^{\alpha}$ and $\mathrm{u}_{\mathrm{sp1}}{ }^{\beta}$ are the "fundamental positive 
sequence components" of grid voltage in $\alpha \beta$ frame. The response time and bandwidth of PSSR are controlled by the constant $\mathrm{K}$.

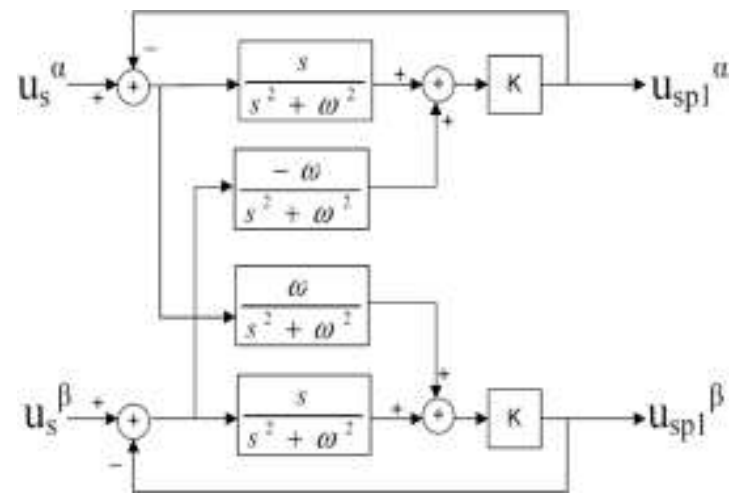

Figure 4. Schematic diagram of PSSR

The fundamental components of load current are calculated using self-tuning filter (STF) as shown in Figure 5, where, $\mathrm{K}$ is the sensitivity parameter of STF; and $\omega$, the fundamental frequency. The advantage of using STF is that there is no phase lag between input and output in an STF like conventional low pass filters [15]. The magnitude and phase plots of $\mathrm{H}(\mathrm{s})$ for different values of $\mathrm{K}$ are shown in Figure 6.

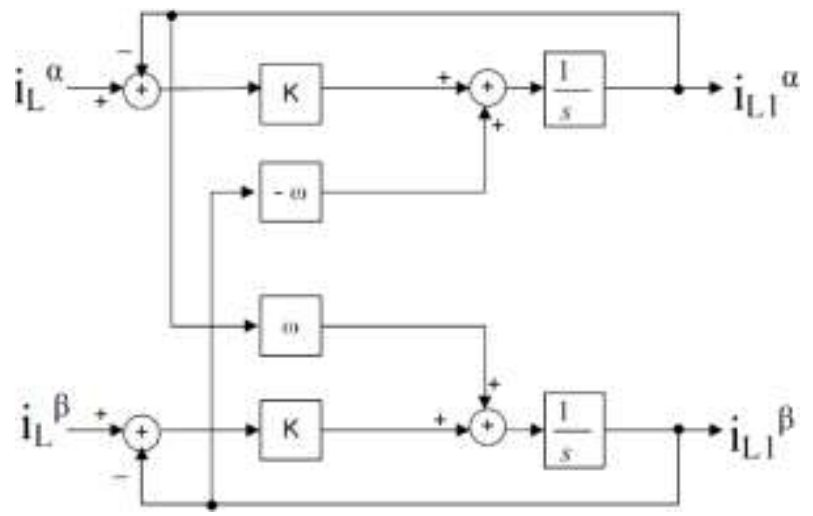

Figure 5. Schematic diagram of STF

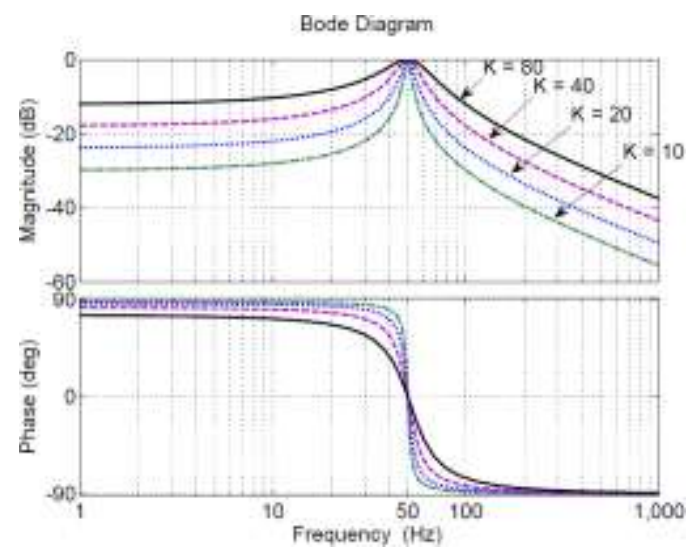

Figure 6. Bode plot of transfer function of STF

$i_{L I}^{\alpha}, i_{L I}{ }^{\beta}$ are the fundamental components of load currents. The harmonic currents $i_{L h}{ }^{\alpha}, i_{L h}{ }^{\beta}$ 
are calculated by subtracting fundamental load current from total load current.

Equation (5) calculates the instantaneous harmonic real power and (6) calculates instantaneous imaginary. The negative sign indicates power flows from the inverter to PCC as seen in Figure 2.

$$
\begin{aligned}
& p_{h}(t)=-\left(i_{L h}^{\alpha} u_{s p 1}^{\alpha}+i_{L h}^{\beta} u_{s p 1}^{\beta}\right) \\
& q(t)=-\left(i_{L}^{\beta} u_{s}^{\alpha}-i_{L}^{\alpha} u_{s}^{\beta}\right)
\end{aligned}
$$

The power calculated in outer loop, $\mathrm{P}_{\mathrm{dc}}-\mathrm{P}_{\mathrm{RES}}$ is added with the instantaneous harmonic real power $\mathrm{p}_{\mathrm{h}}(\mathrm{t})$, and the reference currents for compensation are calculated using (7), where $\mathrm{K}_{\alpha \beta}=$ $\left(\mathrm{u}_{\mathrm{sp1}}\right)^{2}+\left(\mathrm{u}_{\mathrm{sp1}}\right)^{2}$.

$$
\left[\begin{array}{c}
i_{f}^{\alpha} \\
i_{f}^{\beta} \\
i_{f}^{0}
\end{array}\right]=\frac{1}{K_{\alpha \beta}}\left[\begin{array}{ccc}
u_{s p 1}^{\alpha} & -u_{s p 1}^{\beta} & 0 \\
u_{s p 1}^{\beta} & u_{s p 1}^{\alpha} & 0 \\
0 & 0 & K_{\alpha \beta}
\end{array}\right]\left[\begin{array}{c}
p_{h}+p_{d c}-p_{R E S} \\
q \\
i_{0}
\end{array}\right]
$$

The three phase filter currents are calculated using (8).

$$
\left[\begin{array}{c}
i_{f}^{a} \\
i_{f}^{b} \\
i_{f}^{c}
\end{array}\right]=\sqrt{\frac{2}{3}}\left[\begin{array}{ccc}
1 & 0 & 1 / \sqrt{2} \\
-1 / 2 & \sqrt{3} / 2 & 1 / \sqrt{2} \\
-1 / 2 & -\sqrt{3} / 2 & 1 / \sqrt{2}
\end{array}\right]\left[\begin{array}{c}
i_{f}^{\alpha} \\
i_{f}^{\beta} \\
i_{f}^{0}
\end{array}\right]
$$

The reference currents $i_{f}{ }^{\text {abcn }}$ are compared with inverter currents $i_{c}{ }^{\text {abcn }}$, and the gating signals are generated using hysteresis control. The working of hysteresis controller is illustrated using Figure 7 [16].

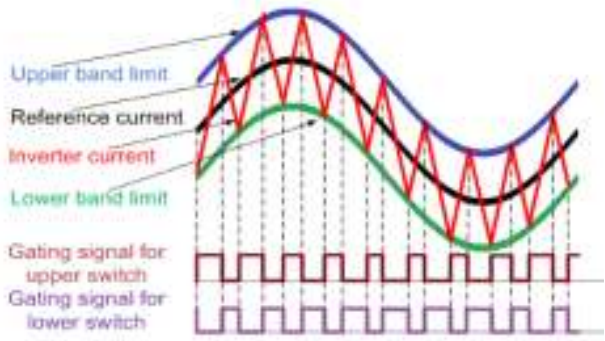

Figure 7. Gating signal generation using hysteresis control

\section{Simulation Results and discussion}

Numerical simulations are carried out in MATLAB/Simulink platform with dynamic models of wind and solar systems. The system parameters used in the simulation are listed in Table 2.

Table 2. System parameters considered for simulation

\begin{tabular}{|c|l|l|}
\hline Sl. no & \multicolumn{1}{|c|}{ Particulars } & \multicolumn{1}{c|}{ Values } \\
\hline 1 & Supply Voltage & $3 \varphi, 415 \mathrm{~V}, 50 \mathrm{~Hz}$ \\
\hline 2 & Source Parameters & $0.01 \mathrm{mH}, 0.1 \Omega$ \\
\hline 3 & $\begin{array}{l}\text { Load Parameters (3 phase diode } \\
\text { bridge rectifier with RL load) }\end{array}$ & $60 \mathrm{mH}, 20 \Omega$ \\
\hline 4 & DC-Link Capacitance & $2350 \mu \mathrm{F}$ \\
\hline 5 & DC-Link Voltage & $700 \mathrm{~V}$ \\
\hline 6 & Filter Parameters & $5 \mathrm{mH}, 0.1 \Omega$ \\
\hline
\end{tabular}

The rated power generation from the hybrid renewable system is considered as $90 \mathrm{~kW}$ (at a 
wind speed of $12 \mathrm{~m} / \mathrm{s}$ and solar irradiation $1 \mathrm{kWm}^{-2}$ ). Both steady-state and dynamic system conditions are simulated and tested the performance of the proposed controller. The results are shown in Figure 8 - 13.

\section{A. Steady-state Conditions}

Case 1: Distortion in grid voltage

A non-sinusoidal grid voltage of voltage harmonics $5 \%$ THD is simulated in this case at 0.5 s. Wind speed is considered as $12 \mathrm{~m} / \mathrm{s}$ and solar irradiation is considered as $1 \mathrm{~kW} / \mathrm{m}^{2}$. A load of $20 \Omega, 60 \mathrm{mH}$ is considered. The DC link voltage remains constant in this case as shown in Figure 8(a). Real powers and reactive powers are unaltered as shown in Figure 8(b), 8(c) and 8(d). The load inverter currents for phase A are shown in Figure 9(a) and 9(b). The grid current and grid voltage for phase A are shown in Figure 9(c). Figure 9(d) is the zoomed-in version of 9(c). The grid current THD is within the limit by compensation. Grid currents with SRF and pq theory with the conventional LPF, and pq theory with STF and PSSR based proposed inner loop controller are shown in Figure 10(a), (b) and (c). It is observed that the grid current THD is minimum with the proposed controller. So it can be concluded that the controller performance is satisfactory under the distorted grid voltage condition.

(a) DC link voltage

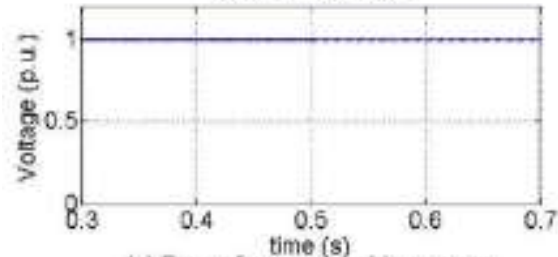

(c) Power from renewable sources

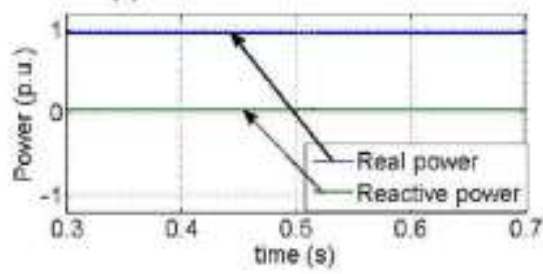

(b) Power from grid

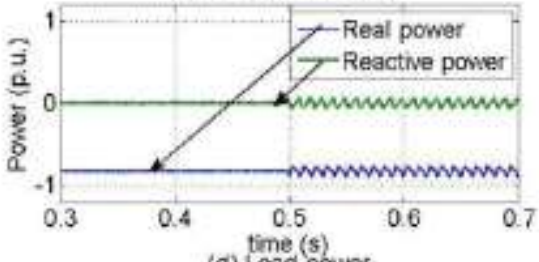

(d) Load powver

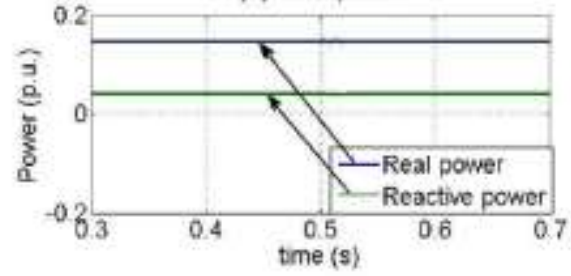

Figure $8 . \mathrm{V}_{\mathrm{DC}}$ and power curves for case 1: Distortion in grid voltage

(a) Load current

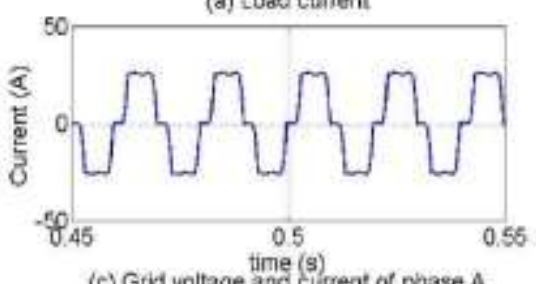

(c) Grid voltage and current of phase A

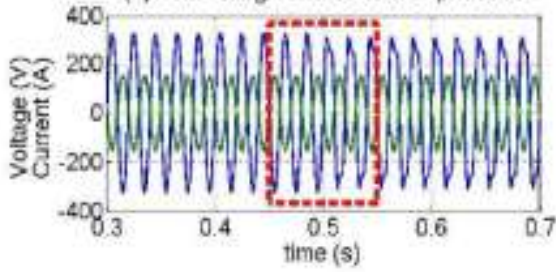

(b) inverter curtent

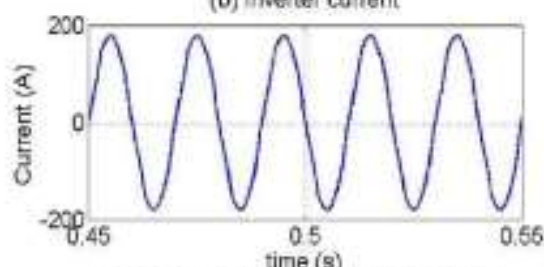

(d) Grid woitage and current of phase A

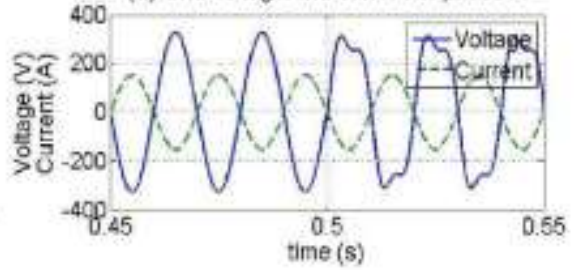

Figure 9. Current and voltage waveforms for case 1: Distortion in grid voltage 
a) with SRF Control

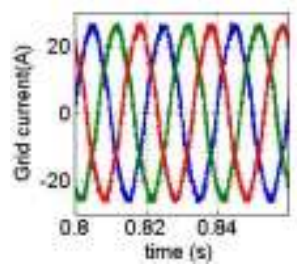

b) with pq Coatrol with L.PF

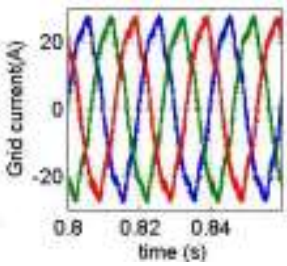

c) with pq Coutrol with STF and PSSR

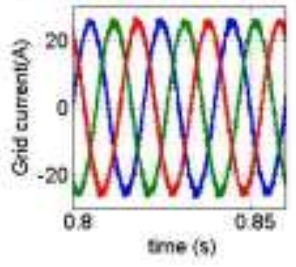

Figure 10. Grid currents with different controllers for case 1: Distortion in grid voltage

Case 2: Unbalance in grid voltage

An unbalanced grid voltage condition is simulated by changing the magnitude of A phase voltage to $120 \%$ at $0.5 \mathrm{~s}$. Wind speed is considered as $12 \mathrm{~m} / \mathrm{s}$ and solar irradiation is considered as $1 \mathrm{~kW} / \mathrm{m}^{2}$. A load of $20 \Omega, 60 \mathrm{mH}$ is considered. DC link voltage is kept at 1 p.u. as shown in Figure 11(a). Real and reactive powers have not changed with unbalance in grid voltage as shown in Figure 11(b) and 11(c). The load and inverter currents for phase A are shown in Figure 12(a) and 12(b). The grid current and grid voltage for phase A are shown in Figure 12(c). Figure 12(d) is the zoomed-in version of 12(c). It is observed that the grid current THD is within the limit by compensation. Grid currents with SRF and pq theory with the conventional LPF, and pq theory with STF and PSSR based proposed inner loop controller are shown in Figure 13(a), (b) and (c). The grid current THD is minimum with the proposed controller. So it can be concluded that the controller performance is satisfactory under unbalanced grid voltage condition.

(a) DC link voltage

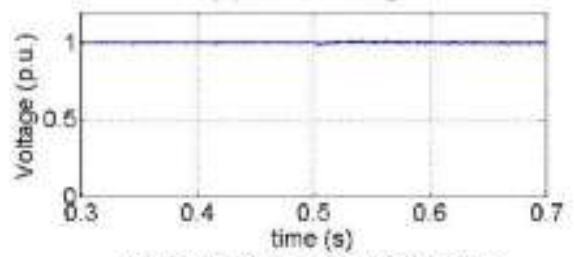

(c) Power from renewable sources

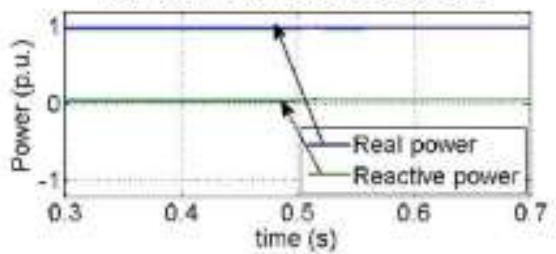

(b) Power from grid

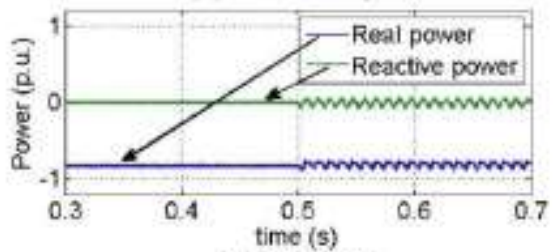

(d) Load power

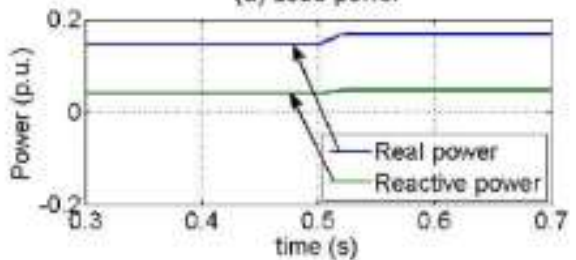

Figure 11. $\mathrm{V}_{\mathrm{DC}}$ and power curves for case 2: Unbalance in grid voltage
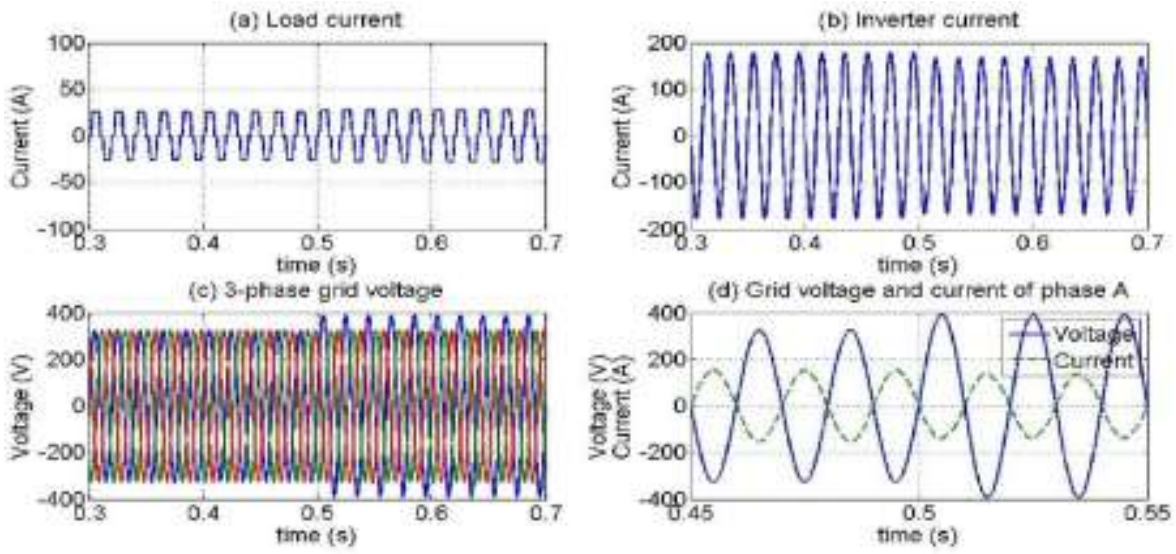

Figure 12. Current and voltage waveforms for case 2: Unbalance in grid voltage 
The steady-state results are summarized in Table 3. The proposed controller has superior harmonic current mitigation property compared to SRF and pq theory-based controllers with conventional LPF.
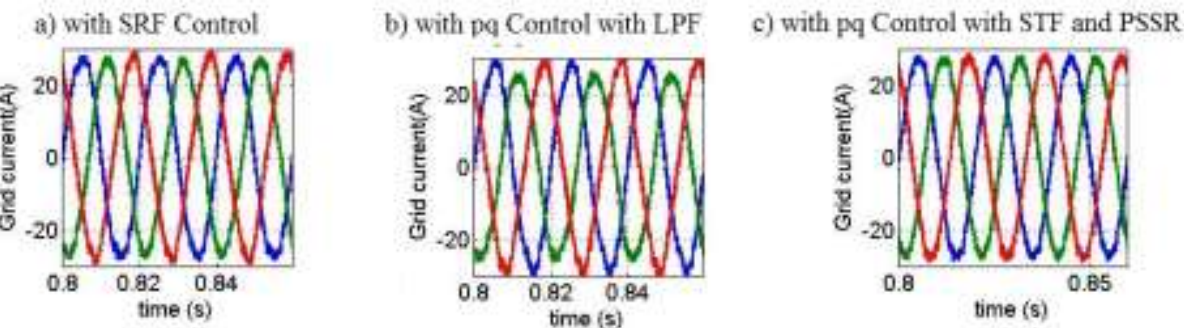

Figure 13. Grid currents with different controllers for case 2: Unbalance in grid voltage

Table 3. Grid current THDs before and after compensation

\begin{tabular}{|c|c|c|c|c|c|c|c|}
\hline \multirow[t]{2}{*}{ Case } & \multirow{2}{*}{$\begin{array}{l}\text { Inner Loop Controller } \\
\text { used }\end{array}$} & \multicolumn{3}{|c|}{$\begin{array}{c}\text { Before } \\
\text { compensation }\end{array}$} & \multicolumn{3}{|c|}{ After compensation } \\
\hline & & $\mathrm{A}$ & B & $\mathrm{C}$ & $\mathrm{A}$ & $B$ & $\bar{C}$ \\
\hline \multirow{3}{*}{$\begin{array}{l}\text { Distorted } \\
\text { grid voltage }\end{array}$} & $\begin{array}{l}\text { SRF theory based } \\
\text { controller with LPF }\end{array}$ & \multirow{3}{*}{22.29} & \multirow{3}{*}{22.29} & \multirow{3}{*}{22.29} & 5.71 & 5.74 & 5.73 \\
\hline & $\begin{array}{c}\text { pq theory based } \\
\text { controller with LPF }\end{array}$ & & & & 10.59 & 10.58 & 10.58 \\
\hline & $\begin{array}{c}\text { pq theory based } \\
\text { controller with STF and } \\
\text { PSSR }\end{array}$ & & & & 0.58 & 0.58 & 0.59 \\
\hline \multirow{3}{*}{$\begin{array}{l}\text { Unbalanced } \\
\text { grid voltage }\end{array}$} & $\begin{array}{l}\text { SRF theory based } \\
\text { controller }\end{array}$ & \multirow{3}{*}{20.46} & \multirow{3}{*}{23.45} & \multirow{3}{*}{23.45} & 4.53 & 4.54 & 4.50 \\
\hline & $\begin{array}{c}\text { pq theory based } \\
\text { controller with LPF }\end{array}$ & & & & 11.24 & 9.54 & 9.82 \\
\hline & $\begin{array}{c}\text { pq theory based } \\
\text { controller with STF and } \\
\text { PSSR }\end{array}$ & & & & 3.5 & 1.68 & 3.53 \\
\hline
\end{tabular}

\section{B. Dynamic Conditions}

\section{Case 3: Step change of load}

A step-change in load is simulated by increasing the load by $100 \%$ at $0.5 \mathrm{~s}$. The generation from renewable sources is considered as unaltered in this case. Wind speed is considered as 12 $\mathrm{m} / \mathrm{s}$ and solar irradiation is considered as $1 \mathrm{kWm}^{-2}$. A load of $20 \Omega, 60 \mathrm{mH}$ is present at the load center. DC-link voltage is unaltered and maintained at 1 p.u as shown in Figure 14(a). It can be observed from 14 (b), (c) and (d) that, as the load increases the power flow from renewable energy sources to grid decreases. More power from renewable sources flows to the load, and excess power flows to the grid. The reactive power demand is completely supplied by renewable sources. The non-linear load current for phase A is shown in Figure 15(a). The compensating current injected by the inverter is shown in Figure 15(b). Figure 15(c) shows the phase A grid voltage and grid current. Figure 15(d) is the zoomed-in version of 15(c). It can be observed that grid current THD is within the limits by the controller action. As load current increases, current to the grid from renewable energy sources decreases, for a constant renewable power generation. 
(a) DC link woltage

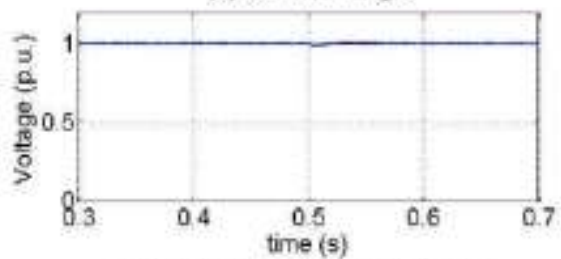

(c) Powver from renewable sources

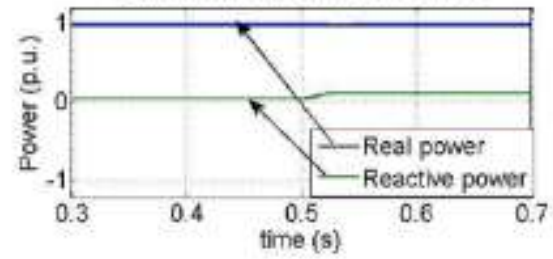

(b) Power from gria

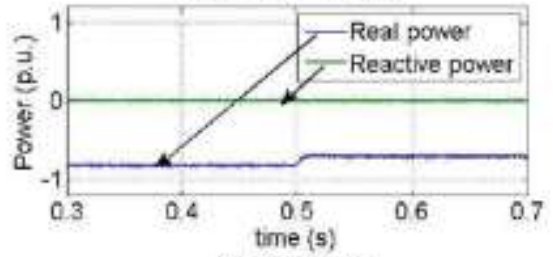

(d) Load power

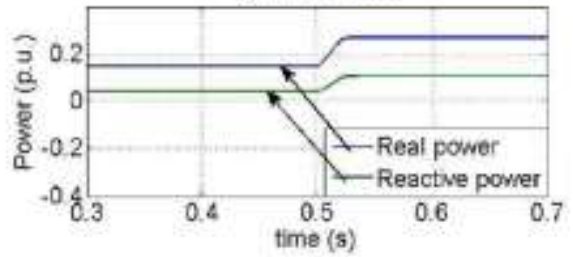

Figure 14. $V_{D C}$ and power curves for case 3: Step change in load
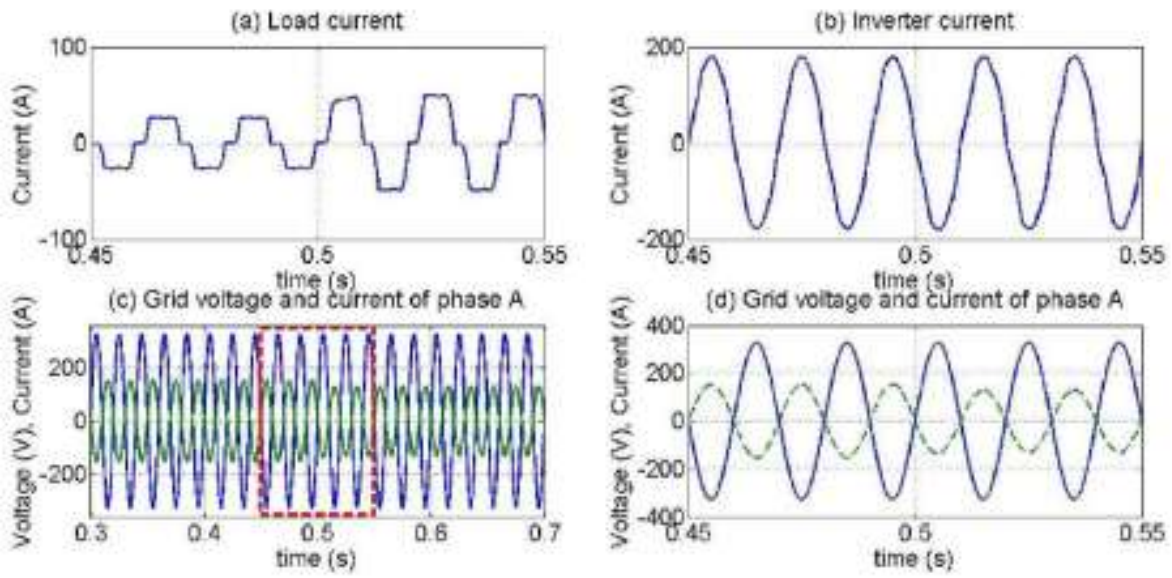

Figure 15. Current and voltage waveforms for case 3: Step change in load

\section{Case 4: A step change in Renewable Power Generation}

A step-change in wind speed and solar irradiation are simulated at $0.4 \mathrm{~s}$ and $0.8 \mathrm{~s}$ respectively. Wind speed is changed from $12 \mathrm{~m} / \mathrm{s}$ to $6 \mathrm{~m} / \mathrm{s}$ and solar irradiation is changed from $1 \mathrm{kWm}^{-2}$ to $0.5 \mathrm{kWm}^{-2}$. A load of $20 \Omega, 60 \mathrm{mH}$ is present at the load center. The dc-link voltage is maintained constant as shown in Figure 16(a). Figure 16(b), (c) and (d) are real and reactive power plots. It is observed that, as a result of decrement in the renewable power generation, the RES to grid power flow reduces. The reactive power demand at the load center is completely supplied by RES. The load current is non-sinusoidal as shown in Figure 17(a). The compensation current reduces as the wind generation and solar generation decreases as shown in Figure 17(b). THD is maintained within the limits by the controller action and reduces its magnitude with a reduction in renewable generation with constant load demand. Grid voltage and current are out of phase by $180^{\circ}$ as power is injected in to the grid as shown in Figure 17(c) and (e). 
(a) DC link voltage

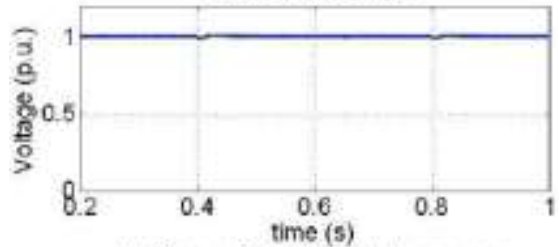

(c) Power from renewable sources

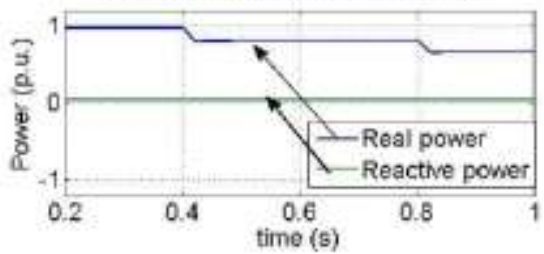

(b) Power from grid

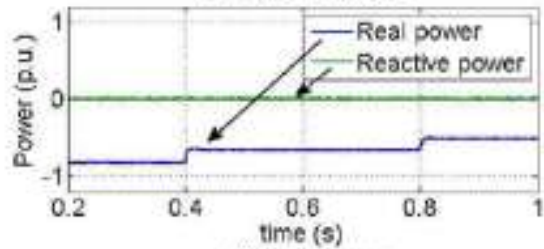

(d) Load power

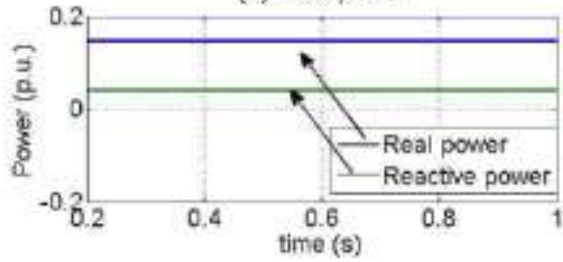

Figure 16. $\mathrm{V}_{\mathrm{DC}}$ and power curves for case 4: Step change of wind speed and solar Irradiation
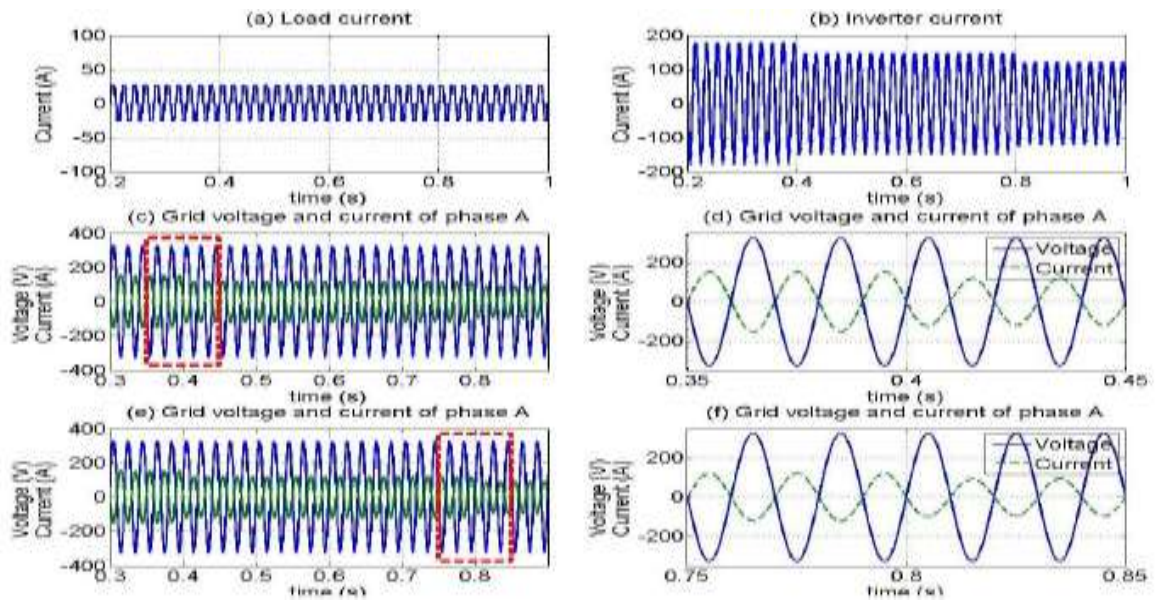

Figure 17. Current and voltage waveforms for case 4: Step change of wind speed and solar Irradiation

Case 5: Renewable generation becomes zero

In this case, the renewable energy generation becomes zero at $0.5 \mathrm{~s}$. A load of $20 \Omega, 60 \mathrm{mH}$ is present at the load centre. A small dip in dc-link voltage can be observed at $0.5 \mathrm{~s}$ in Figure 18(a). After some milliseconds, it comes back to 1 p.u. by the control action. Figure 18(b), (c) and (d) shows the real and reactive power plots. It can be observed that RES power falls to zero and the grid power becomes positive. The grid supplies power to meet the load demand when the RES generation is absent. From the reactive power plots, it can be seen that inverter is still capable of providing reactive power to the load. The load current as shown in Figure 19(a) remains the same, but inverter current, shown in fig Figure 19(b) magnitude and direction changes at $0.5 \mathrm{~s}$. Magnitude and direction of grid current changes as shown in Figure 19(c). The sinusoidal shape of the grid current is still preserved by the controller action. 
(a) DC link voltage

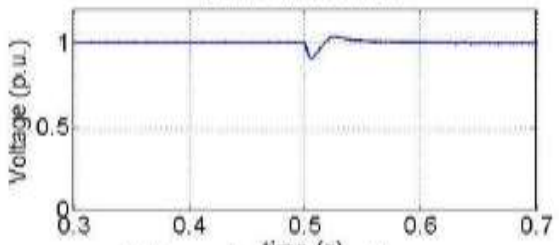

(c) Power from time (s)

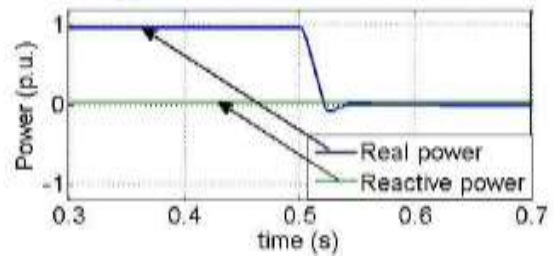

(b) Power from grid

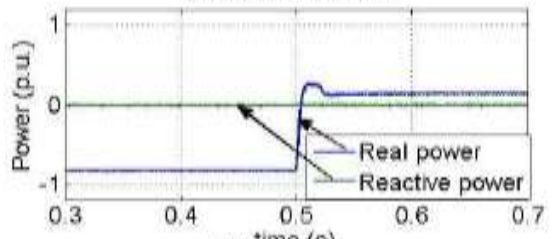

(d) Load power

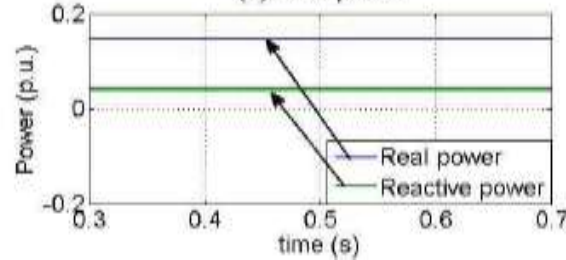

Figure $18 . \mathrm{V}_{\mathrm{DC}}$ and power curves for case 5: Renewable generation becomes zero
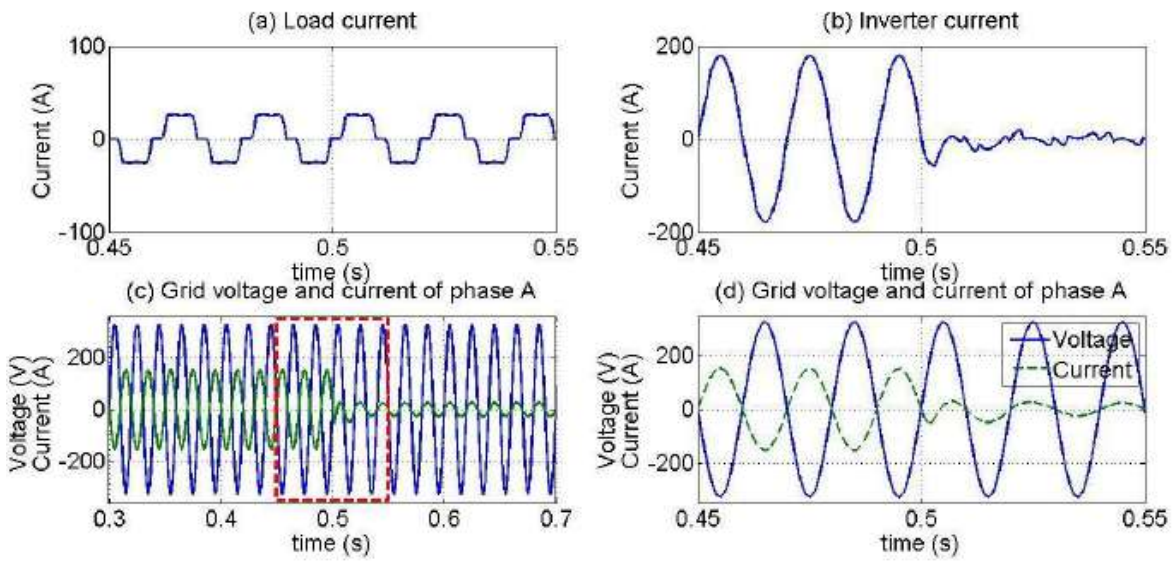

Figure 19. Current and voltage waveforms for case 5: Renewable generation becomes zero

It can be observed that the THD values of grid current for different cases are below $5 \%$ in all cases, which is within the limit of permissible current THD according to IEEE-519 standard of power quality [17].

From the simulation results, it can be concluded that the three-phase four-leg inverter with proposed controller effectively fulfills the following duties.

- controls the power flow

- reduces THD of grid current

- balances grid current

- supplies reactive power.

\section{Hardware Results}

The Xilinx (XC7a35t cpg236-1) FPGA is used for implementing the proposed control algorithm. Hall-effect sensors LEM LV-25p and LEM LA-55p are the voltage and current sensors used respectively. The shunt active filter is realized using IGBT inverter (SKM75GB12T4) with SKYPER32R gate driver. The system parameters are shown in Table 4. 
Table 4. System parameters considered for hardware implementation

\begin{tabular}{|c|l|l|}
\hline Sl. no & \multicolumn{1}{|c|}{ Particulars } & \multicolumn{1}{c|}{ Values } \\
\hline 1 & Supply Voltage & $1 \varphi, 30 \mathrm{~V}, 50 \mathrm{~Hz}$ \\
\hline 2 & $\begin{array}{l}\text { Load Parameters (1 phase diode } \\
\text { bridge rectifier with RL load) }\end{array}$ & $48 \mathrm{mH}, 10 \Omega$ \\
\hline 3 & DC-Link Capacitance & $2350 \mu \mathrm{F}$ \\
\hline 4 & DC-Link Voltage & $50 \mathrm{~V}$ \\
\hline 5 & Filter Parameters & $8.3 \mathrm{mH}, 0.06 \Omega$ \\
\hline
\end{tabular}

The proposed controller employed with PSSR and STF is compared with the conventional LPF based controller. Figures 19 and 20 show the steady-state voltage \& current waveforms and their frequency spectrum respectively.

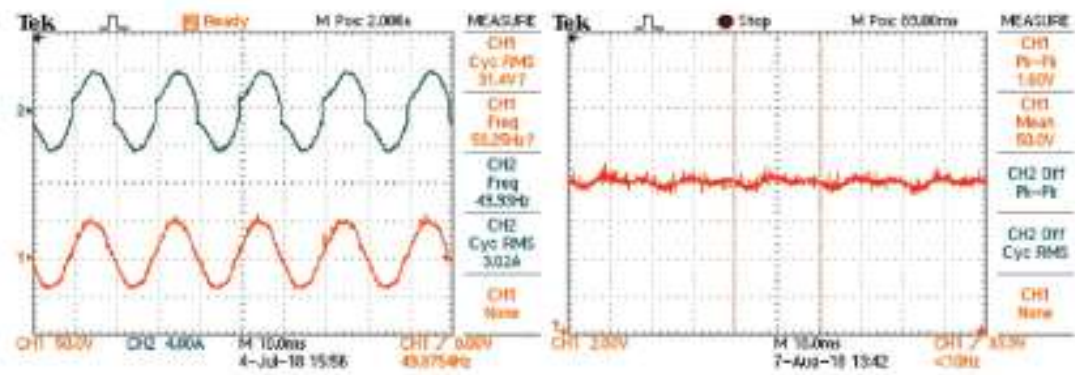

a) Load current and grid voltage

b) DC-link voltage

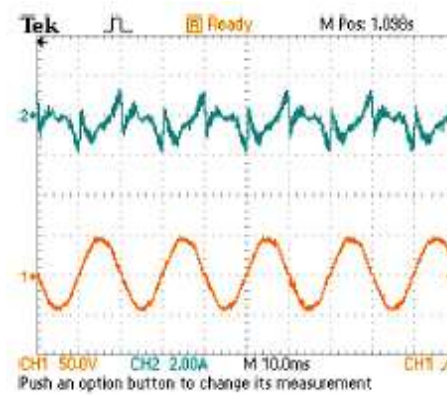

c) Compensation current and grid voltage (with LPF based pq theory control)

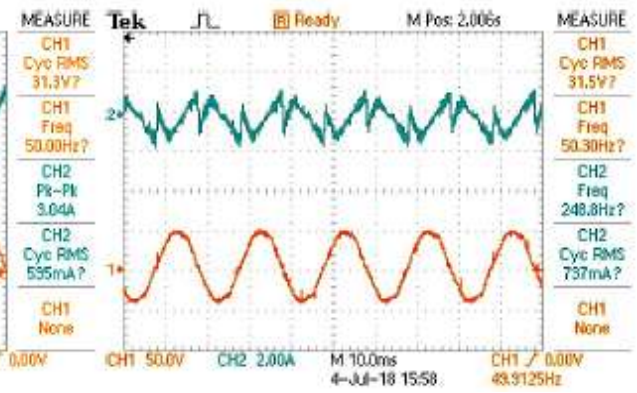

d) Compensation current and grid voltage (with PSSR-STF based pq theory control)

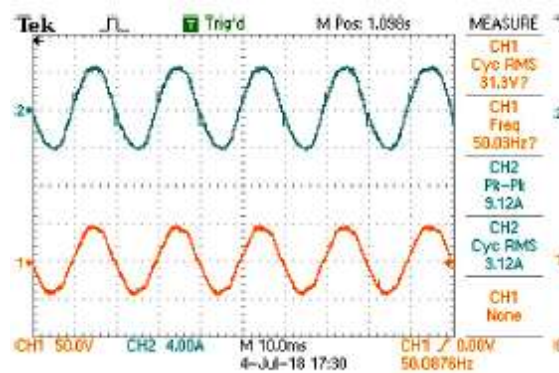

e) Grid current and grid voltage (with LPF based pq theory control)

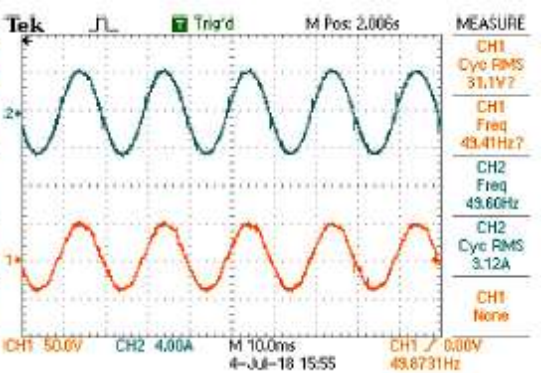

f) Grid current and grid voltage (with PSSR-STF based pq theory control)

Figure 19. Hardware results for steady state condition under distorted grid voltage with LPF based pq theory and STF-PSSR based pq theory controllers 


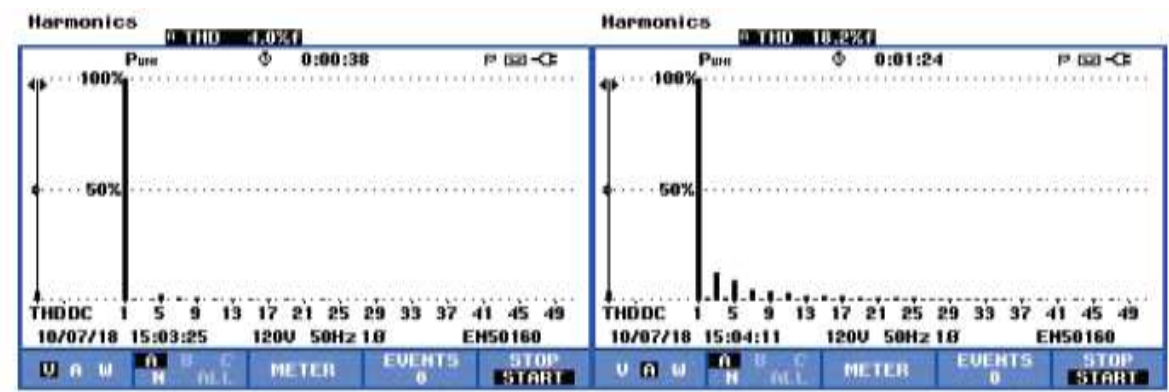

a) Frequency spectrum of grid voltage b) Frequency spectrum of Load current

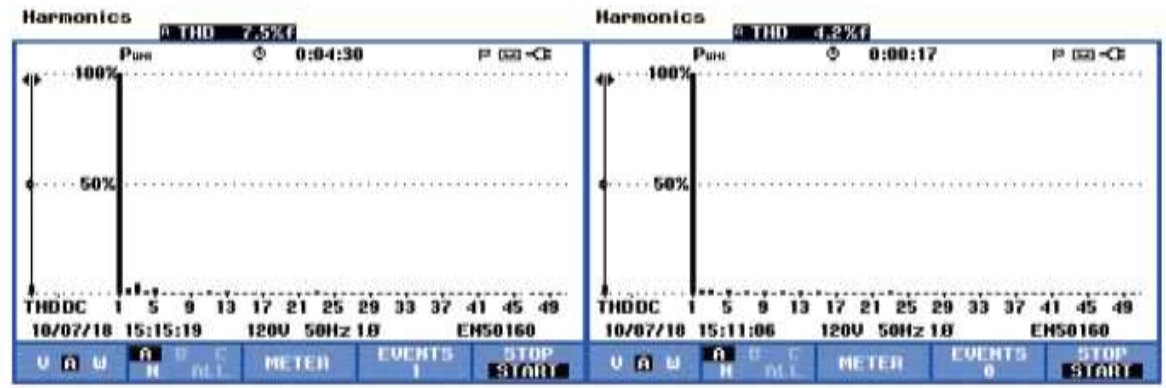

c) Frequency spectrum of Grid current b) Frequency spectrum of Grid current (with LPF based pq theory control) (with PSSR-STF based pq theory control)

Figure 20. Harmonic analysis results for steady state condition under distorted grid voltage with LPF based pq theory and STF-PSSR based pq theory controllers

Load current and grid voltage THDs are $18.2 \%$ and $4 \%$ respectively. The grid current THD is to $4.2 \%$ with the proposed controller, whereas it is $7.5 \%$ with the conventional LPF based controller, which shows that the proposed controller offers superior performance at steady-state.

\section{Conclusion}

A dynamic model of wind-solar hybrid system has been simulated in MATLAB/Simulink platform. The grid integration of the wind-solar hybrid system with shunt active filtering, in dc shunted topology, has been studied and modeled. A novel control strategy with an adaptive fuzzy logic controller in the outer loop and modified instantaneous theory in the inner loop has been employed. The controller performance is validated under different dynamic conditions such as load change, change in renewable generation, absence of renewable generation, unbalance in load, etc. The proposed controller works satisfactorily under distorted and unbalanced grid voltage conditions without using any phase-locked loop circuits (PLL). Significant contributions of this study are:

- Successful employment of adaptive fuzzy logic for the control of dc-link.

- Successful implementation of modified instantaneous power theory with PSSR and STF.

- Successful implementation of the inverter controller with the dual responsibility of grid interfacing and shunt active filtering.

- Successful verification of the controller's performance with a laboratory prototype.

\section{Acknowledgements}

The authors would like to thanks the Ministry of Human Resource Development, Govt. of India for the financial support to carry out this research work.

\section{References}

[1]. Chen Y. M, Cheng C.S., Wu H. S.: Grid-connected hybrid PV/Wind power generation system with improved DC bus voltage regulation strategy. In: Proceedings of the Twenty 
First Annual IEEE Applied Power Electronics Conference and Exposition, 2006, APEC '06, Dallas, TX, p. 1088-1094.

[2]. Akagi H., Kanazawa Y., Nabae A.: Instantaneous reactive power compensators comprising switching devices without energy storage components. In: IEEE Transactions on Industrial Applications, vol. 20 (1984), May/June 1984, p. 625-630.

[3]. Bhattacharya S., Divan D.: Design and implementation of a hybrid series active filter system. In: Proceedings of 26th Annual IEEE Power Electronics Specialists Conference, PESC '95, June 1995, Atlanta, GA, vol. 1, p. 189-195.

[4]. Yavari M., Sabahi M. and Babaei E.: Enhancement of Instantaneous Power Theory under Unbalanced Grid Voltages Condition Using Positive Sinusoidal Signal Regulator. In: Proceedings of IEEE 5th India International Conference on Power Electronics (IICPE), Dec 2012, Delhi, 2012, p. 1-6.

[5]. Akagi H.: The state-of-the-art of active filters for power conditioning. In: Proceedings of 2005 European Conference on Power Electronics and Applications, Dresden, 2005, p. 115.

[6]. Mikkili S., Panda A. K.: Instantaneous Active and Reactive Power and Current Strategies for Current Harmonics Cancellation in 3-ph 4-Wire SHAF with Both PI and Fuzzy Controllers. In: Energy and Power Engineering, 3 (2011), No. 3, p. 285-298.

[7]. Anderson P. M., Bose A: Stability Simulation Of Wind Turbine Systems. In: IEEE Transactions on Power Apparatus and Systems, PAS-102 (1983), No. 12, Dec. 1983, p. 3791-3795.

[8]. Slootweg J., Haan S. D., Polinder H., Kling W.: General model for representing variable speed wind turbines in power system dynamics simulations. In: IEEE Transactions on Power Systems, 18 (2003), Feb 2003, no. 1, p. 144-151.

[9]. Husain M. A., Tariq A.: Modeling of a standalone Wind-PV Hybrid generation system using MATLAB/ SIMULINK and its performance analysis. In: International Journal of Scientific \& Engineering Research, 4 (2013), November 2013, No. 11, p. 1805-1811.

[10]. Carrasco J. M, Bialasiewicz J. T.: Power- Electronic Systems for the Grid Integration of Renewable Energy Sources: A Survey. In: IEEE Transactions on Industrial Electronics, 53 (2006), August 2006, No. 4, p. $1002-1016$.

[11]. Gow J. A., Manning C. D.: Development of a model for photovoltaic arrays suitable for use in simulation studies of solar energy conversion systems. In: Proceedings of 6th International Conference on Power Electronics and Variable Speed Drives, Sep. 23-25, 1996, p. 69- 74.

[12]. Villalva M. G., Gazoli J. R., Filho E. R.: Comprehensive Approach to Modeling and Simulation of Photovoltaic Arrays. In: IEEE Transactions on Power Electronics, 24 (2009), May 2009, no. 5, p. 1198- 1208.

[13]. Tan K. T., So P. L., Chu Y. C., Kwan K. H.: Modeling, Control and Simulation of a Photovoltaic Power System for Grid-connected and Stand-alone Applications. In: Proceedings of IPEC, IPEC10, October 2010, p. 608- 613.

[14]. Nejabatkhah F., Li Y. W., Wu B.: Control Strategies of Three-Phase Distributed Generation Inverters for Grid Unbalanced Voltage Compensation. In: IEEE Transactions on Power Electronics, 31 (2016), July 2016, no. 7, p. 5228-5241.

[15]. Benchouia M.T., Ghadbane I., Golea A., Srairi K., Benbouzid M. E. H: Implementation of adaptive fuzzy logic and PI controllers to regulate the DC bus voltage of shunt active power filter. In: Applied Soft Computing, 28 (2015), March 2015, p. 125-131.

[16]. Ingram D. M. E., Round S. D.: A novel digital hysteresis current controller for an active power filter. In: Proceedings of International Conference on Power Electronics and Drive Systems, 1997, vol. 2., p. 744-749.

[17]. IEEE Recommended Practices and Requirements for Harmonic Control in Electrical Power Systems (1993). In: IEEE Std 519-1992, April 9, 1993, vol., no., p. 1-112. 


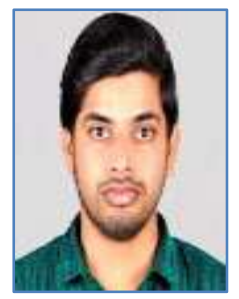

Jayasankar $\mathbf{V} \mathbf{N}$ received his B.Tech degree in Electrical \& Electronics Engineering from Kannur University, India in 2010, M.Tech degree in Power Systems from National Institute of Technology Calicut, India in 2012 and Ph.D. from National Institute of Technology Karnataka, Surathkal, India in 2019. He has worked in Power Development \& Research Consultants Pvt. Ltd. Bengaluru as Engineer; Power System Studies. He is currently working as Assistant Professor in the Department of Electrical \& Electronics Engineering, The National Institute of Engineering Mysuru, India. His research interests include Renewable Energy, Power Electronics and Power Quality.

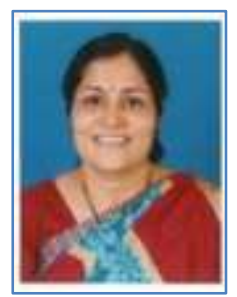

Vinatha $\mathbf{U}$ received her B.Tech in Electrical \& Electronics Engineering from KREC Surathkal, Mangalore University in 1986, M.Tech in Industrial Electronics from KREC Surathkal, Mangalore University in 1992, and the $\mathrm{PhD}$ in Electrical Engineering from National Institute of Technology Karnataka Surathkal, India in 2013. She is currently an Associate Professor in National Institute of Technology Karnataka Surathkal, India. Her research interests include Power Electronics and Drives, Power Electronic Converters in Renewable Systems, Multilevel Inverters, and Wave Energy Conversion System. She is a senior IEEE member. 